\title{
Diferentes formas de ler: reflexões sobre práticas sociais de leitura na grande Florianópolis
}

\author{
Eliane Santana Dias Debus \\ UNISUL
}

\section{Resumo}

Este artigo socializa os resultados do projeto integrado às atividades da disciplina Leitura e Produção Textual, realizado com alunos da $1^{\text {a }}$ fase do Curso de Pedagogia da UNISUL. A pesquisa teve como objetivo fazer refletir sobre as concepções de leitura e as práticas correntes de leitura que circulam na sociedade contemporânea, partindo da ideia de que o estudo sobre a leitura realizada fora do espaço escolar também merece e precisa ser construído.

Palavras-chave: leitura, leitor, práticas de leitura.

\section{Abstract}

This article presents results of a project integrated with the activities of the subject Reading and Text Production and conducted with students from the first semester of Pedagogy at UNISUL. The study aims to reflect on conceptions of reading and everyday practices of reading highlighted in contemporary society, and it derives from the idea that the study of reading outside the school also deserves and needs to be constructed.

Key words: reading, reader, practices of reading.

\section{INTRODUÇÃO}

Não parece razoável [...] que se continue a pensar apenas nas obras consagradas, nos grandes escritores e pensadores. É preciso conhecer as leituras correntes, aquelas que pessoas comuns realizam em seu cotidiano. E sobre isso pouco sabemos (Abreu, 2001).

Paulo Freire (1982), ao tecer uma arqueologia da leitura, propriamente a sua, no artigo “A importância do ato de ler”, destaca a necessidade de atentarmos para as leituras de mundo que, na maioria das vezes, antecedem a leitura da palavra escrita. Num discurso 
carregado de poeticidade, ele nos descreve a leitura da natureza: as cores das frutas, em especial da manga e todos os seus rosados; as nuvens que no céu se esticam e brincam de virar personagens; as cascas das árvores repletas das marcas do tempo; a manha dos animais da casa, gatos e cachorros; dos homens com seus falares e caminhares. O escritor traz para a cena até mesmo o ler as coisas não visíveis como as assombrações e os medos de seres de outros mundos.

Esse artigo de Paulo Freire foi socializado pela primeira vez em formato de conferência no Congresso de Leitura do Brasil (COLE - 1981). Nele, o estudioso tece considerações não sobre a leitura do objeto livro (leitura sensorial) e nem da palavra (a letra impressa) e sim, das coisas que nos rodeiam (o mundo). Esse exercício de leitura de mundo propiciaria, segundo ele, um alargamento na aprendizagem da leitura escrita. A sensibilidade para ver o(s) outro(s) nos constitui e nos constrói no que gostaria de chamar aqui de "seres de leitura”, capazes de ler os textos da vida cotidiana.

Contemporaneamente, as concepções relativas à leitura do texto escrito, seja literário ou não, vêm acompanhadas de algumas certezas, entre elas a de que é mais adequado ler em silêncio e recolhidamente; deve-se ler em abundância o maior número de títulos possíveis; a leitura literária deve ser entendida como promotora da formação leitora. No entanto, será que as práticas de leitura do texto escrito sempre foram como as concebemos hoje? Abreu (2001) desconstrói essas certezas cristalizadas contemporaneamente ao visitar a história da leitura em seu texto "Diferentes formas de ler".

No caso da leitura silenciosa, a autora argumenta que ler com os olhos, silenciosamente, é a imagem primeira que surge em nossa mente quando pensamos no ato da leitura. No entanto, ler em voz alta foi uma prática que perdurou até o século XIV, embora alguns casos de leitura silenciosa sejam relatados, como no depoimento de Santo Ambrósio ao observar a leitura de língua quieta de Santo Agostinho (século VI d.C.). A leitura oralizada fazia parte do convívio social, reunia indivíduos em torno do ato de ler.

Diferentemente de hoje que se valoriza a leitura do maior número possível de títulos, durante séculos esta prática era inviabilizada, pois a quantidade de livros era restrita, fato que levava o indivíduo leitor a retornar, por várias vezes, ao mesmo título, em especial os religiosos, efetivando, assim, uma leitura intensiva. Abreu (2001), em seu estudo sobre as diferentes formas de ler ao longo da história, apresenta as ideias do médico suíço Tissot, 
desenvolvidas em publicação do século XVIII, que desaconselhava a leitura extensiva e apontava como caminho para a saúde, em especial a mental, ler pouco e fazer exercícios.

Até o século XVIII, era temerário valorizar a leitura literária, em especial para as mulheres, pois se supunha que a identificação com as personagens e o devaneio da leitura poderia levá-las a atentar contra a moral.

No entanto, a partir do final do século XVIII e ao longo do XIX, a imagem de leitura retratada nas pinturas a trazia como símbolo de status e o acesso ao livro como uma demonstração de poder intelectual e econômico. Ainda hoje muitos sites pessoais na internet continuam a propagar esse mesmo vínculo entre leitura e enobrecimento, como observa Abreu (2001): "passaram-se os séculos, alterou-se o meio, mudou a tecnologia, mas o imaginário em torno do ato de ler permanece”.

Como professora na área da linguagem, atuando em cursos de formação de professores, em especial de Pedagogia, acredito ser de fundamental importância colaborar para que os estudantes deste curso, futuros professores, construam um olhar sensível sobre a leitura que nos enreda. É necessário que desenvolvam conhecimentos sobre as diferentes concepções de leitura, bem como valorizem a leitura como fonte de conhecimento e, também, como fonte de fruição estética e entretenimento. Tal perspectiva contribuirá para a ampliação de suas competências leitoras e, consequentemente, de suas competências de escrita.

Nesse sentido, desenvolveu-se o projeto Tantas e quantas formas de ler: reflexões sobre as práticas sociais de leitura, apresentado na modalidade de "Projetos em Disciplina”, que buscou integrar-se às atividades da disciplina Leitura e Produção Textual, realizado com alunos da $1^{\text {a }}$ fase do Curso de Pedagogia da Universidade do Sul de Santa Catarina - UNISUL, Campus da Pedra Branca. Embora tenha sido oficializado como projeto de pesquisa a ser efetivada a partir de 2006.1, descrevem-se, neste texto, atividades realizadas anteriormente a esse período, já desenvolvidas metodologicamente dentro da proposta de pesquisa, em 2004.1, 2005.2 e em 2006.1.

Ao trazer à tona o tema leitura, tem-se como objetivo fazer refletir sobre as concepções e as práticas correntes de leitura que circulam na sociedade contemporânea, partindo da ideia de que o estudo sobre a leitura realizada fora do espaço escolar também 
merece e precisa ser construído. Outros espaços e outras formas de ler são realizados no cotidiano e precisam ser visitados para que não se caia em reducionismos e/ou supervalorização de um tipo de leitura em detrimento de outro.

Metodologicamente, a atividade, desenvolvida em pequenos grupos, se constitui de quatro momentos:

1) Leitura e discussão do referencial teórico em sala de aula, em especial a partir de três textos bases, A importância do ato de ler, de Paulo Freire; Diferentes formas de ler, de Márcia Abreu e Cenas de leitura na pintura, na fotografia, no cartaz, de 1881 a 1989, de Martine Poulain. Esses textos contribuem para sensibilizar o olhar dos alunos para as práticas sociais de leituras que os rodeiam, além da escolar.

2) Levantamento de locais, projetos e/ou pessoas físicas na grande Florianópolis, que possam servir de referência para a pesquisa, partindo-se de uma listagem sugerida pelo professor: a) locais: bibliotecas públicas, bibliotecas escolares, livrarias, shopping centers, ônibus, academias de ginástica, praças, estacionamentos etc.; b) representações: imagens de leitura no cinema, imagens de leitura nas artes plásticas, imagens de leitura em revistas de “fofocas” etc.; c) projetos: Baú de histórias do SESC, Sociedade dos Amantes da Leitura, Roda de histórias - UFSC, Sites na internet específicos sobre leitura (levantamento).

3) Elaboração de questionários a partir da escolha do local, projeto ou sujeito da pesquisa.

4) Utilização da fotografia como registro das práticas de leitura encontradas em diferentes ambientes.

É necessário, ainda, apontar as dificuldades encontradas pelos alunos ao desenvolver este trabalho: a) é realizado num curto período, juntamente com as muitas outras tarefas que os acadêmicos têm a realizar nas outras disciplinas da fase; b) a leitura base destes alunos não comporta reflexões de cunho teórico mais aprofundado, assim as exigências se redimensionam a partir dos limites de cada grupo; c) as dificuldades de elaboração de um trabalho científico sem ainda terem cursado a disciplina de Metodologia Científica.

A seguir, serão apresentados alguns dos trabalhos realizados nos três semestres já referidos, com o intuito de provocar o debate e trazer a reflexão para as práticas de leituras 
que existem e que muitas vezes não percebemos, não nos damos conta da sua existência e, por vezes, não as legitimamos academicamente.

\section{MÚLTIPLOS OLHARES SOBRE LEITURAS MÚLTIPLAS: QUANDO OS ALUNOS SAEM À RUA À PROCURA DO QUE SE LÊ}

A delimitação implícita de um certo conjunto de textos e de determinados modos de ler como válidos e o desprezo aos demais nos cega para grande parte das leituras realizadas no cotidiano (Abreu, 2001).

Pessoa (2004.2) investigou as leituras realizadas na Praça XV de Novembro, situada em Florianópolis. Local turístico que abriga uma figueira de mais de 100 anos, o espaço da Praça é democrático, abriga tanto o morador local como o estrangeiro. A utilização da Praça como espaço propício para a leitura está nos versos do Poeta Zininho, na canção Rancho de amor à Ilha, "Ilha da velha figueira/onde em tarde fagueira/ vou ler meu jornal”.

A partir de fotografias e entrevistas com os indivíduos observados, a aluna constatou que a leitura mais frequente é a do jornal (Fig. 1), o que não exclui outras, como a literária, a científica e de panfletos.

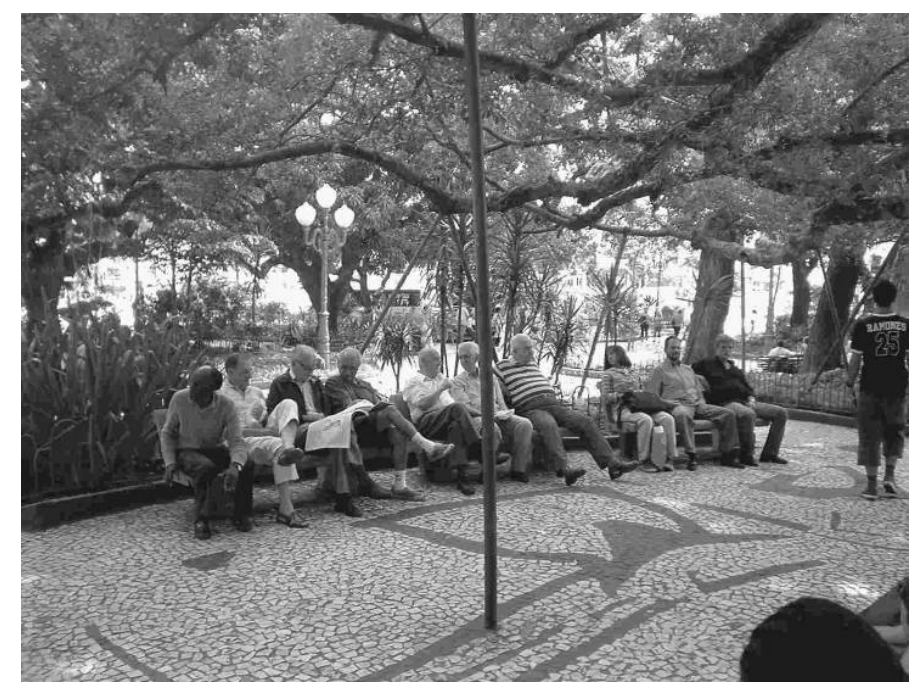

Fig.1 - A leitura na Praça XV de Novembro 
$\mathrm{Na}$ imagem observa-se a leitura compartilhada, senhores da terceira idade, provavelmente já aposentados, lêem e dividem opiniões sobre as notícias lidas. Um único exemplar se multiplica e se faz lido por muitos. Esta é uma prática corriqueira na praça, basta termos os olhos mais atentos e veremos, antes de uma partida de dominó, a leitura coletiva. Seria ela motivada pelo custo econômico do exemplar? Teriam esses leitores adquirido o "vício" da leitura do jornal no seu antigo local de trabalho? Talvez numa repartição pública? Atrás de um balcão no comércio?

Curiosamente, a leitura no espaço público da praça se caracteriza como masculina. São os homens que, despojados, se sentam nos bancos de granito e efetivam suas leituras, seja aquela de cunho imediato, como a leitura de um jornal ou a localização através de um mapa, como aquela mais elaborada, literária ou científica.

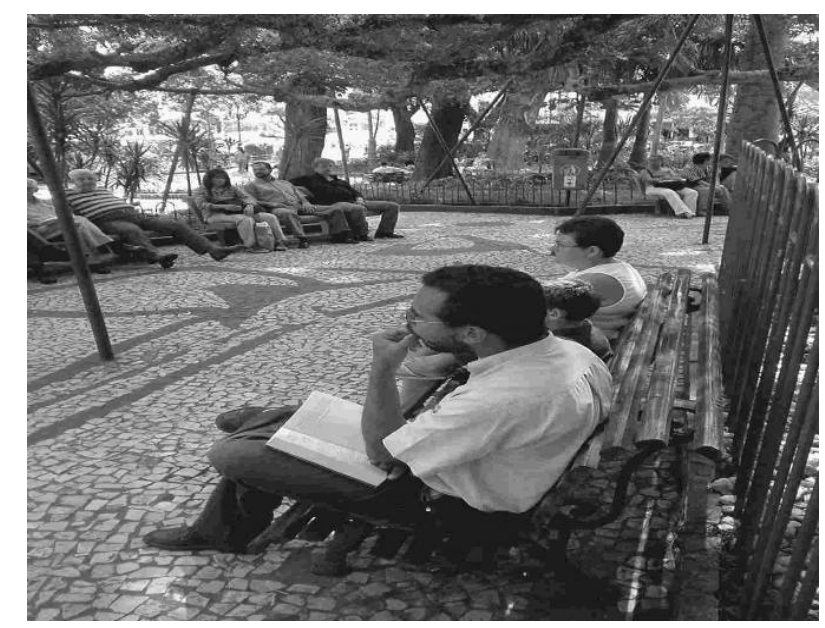

Fig.2 - Ler no burburinho da Praça

O burburinho da praça, com seus moradores ocasionais e passantes, não desconcentra o leitor que atento lê e reflete sobre a leitura realizada (Fig.2). 
A leitura da palavra ficaria circunscrita a olhos vistos? O trabalho "Lendo na ponta dos dedos”, realizado por Ribas \& Ribas (2004.2), apresentou imagens que nos remetem a outro tipo de leitura: a dos cegos (Fig.3).

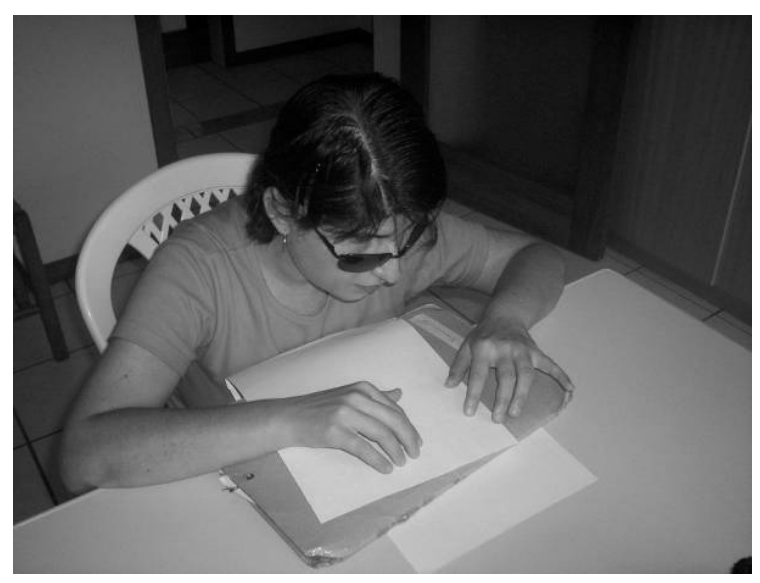

Fig. 3 - Lendo na ponta dos dedos

O trabalho foi desenvolvido na Associação Catarinense para Integração do Cego ${ }^{1}$ (ACIC), localizada no bairro Saco Grande, em Florianópolis.

Na imagem, percebe-se que os protocolos e os gestos de leitura são outros, pois são outras as necessidades. A maior reclamação desse grupo de leitores recai sobre a má qualidade do material produzido. A transcrição do texto para o braile também provoca um certo desconforto no manuseio, já que o texto fica mais volumoso.

O que se lê na estrada além das placas comerciais, outdoors? Qual a leitura mais próxima que não a placa do carro que está na frente? O pára-choque de caminhões se torna, sem sombra de dúvidas, uma leitura na estrada. Cunha (2005.2) entrevistou seis pessoas (1 caminhoneiro, 1 frentista, 1 professora, 1 criança, 1 vendedor e 1 jornalista) que estão na estrada com frequência, e todas elas admitiram a leitura dos pára-choques.

Na resposta dos entrevistados verificou-se que além de fazer a leitura dos dizeres nos pára-choques, todos sabiam de memória mais de duas frases. Constata-se que, mesmo inconscientemente, a leitura feita nas placas encontradas nas estradas nos acompanha.

\footnotetext{
${ }^{1}$ Fundada em 1977, a Associação atende pessoas cegas a partir de 14 anos de idade, com foco principal àquelas que residem no estado de Santa Catarina, no entanto, em alguns casos, encontram-se pessoas até de outros países. A entidade possui 14 alojamentos, que servem como abrigo temporário para aqueles que estão longe de suas casas.
} 
O grupo de alunas Amorim, Dias, Pedro, Carvalho e Bueno (2006.1) pesquisou a leitura realizada pelos idosos do Asilo Irmão Joaquim (Florianópolis). No questionamento a três entrevistados, dois do sexo feminino e um do masculino, constatou-se que as leituras religiosas, como no acompanhamento da liturgia na missa realizada no Asilo, nos folhetos e no texto bíblico, são as mais presentes nesse ambiente marcado pela solidão. Curiosamente, um dos entrevistados foi contatado no espaço externo da Instituição, no ponto de ônibus que se localiza bem em frente ao edifício do Asilo. Cego, a sua leitura se efetiva através do braile.

Apresentamos a seguir, mesmo que de forma breve, os trabalhos realizados pelos alunos e pelas alunas em 2006.2, já inseridos no Projeto em Disciplina de forma sistematizada. Os trabalhos foram realizados em grupo, sendo que dois alunos optaram por fazê-lo individualmente. Na turma do Norte da Ilha, a atividade resultou no total de sete trabalhos, todos realizados em diferentes bairros do município de Florianópolis.

Silva, Conceição e Teixeira (2006.2) investigaram sobre as práticas de leitura realizadas no Shopping Center Beiramar, localizado no centro da cidade, na época único Shopping dentro da Ilha e muito frequentado. As alunas encontraram diferentes tipos de leitura, da leitura rápida de jornal realizada na parada para um cafezinho à leitura de livros dentro da única livraria daquele estabelecimento.

Ferraz (2006.2) pesquisou sobre as práticas de leitura realizadas na Igreja Evangélica Quadrangular, bairro Ingleses. Evangélica e membro do grupo de estudos sobre a Bíblia, a acadêmica descobriu, ao entrevistar um dos leitores do grupo, que ele era analfabeto e que estudava a Bíblia, sabendo seu texto de memória, por meio da audição de fitas cassetes.

Silveira e Pereira (2006.2) verificaram as práticas de leitura realizadas pelos alunos de $1^{\mathrm{a}}$ a $4^{\mathrm{a}}$ série na Biblioteca Escolar do Instituto Estadual de Educação (IEE), maior escola pública de Santa Catarina. As alunas constataram quais os títulos a que os alunos têm acesso, bem como aqueles que eles podem tomar emprestado, observaram a hora do conto realizada naquele espaço e outras dinâmicas de promoção da leitura, em especial a literária.

Silva e Hauptli (2006.2), com o título "Entre sol e mar: as leituras realizadas na Praia de Canasvieiras”, realizaram a investigação na Praia de Canasvieiras. Embora o mês fosse novembro, os alunos encontraram muitas pessoas na praia, pois era final de semana e 
havia sol. Verificaram diversos tipos de leitura, no entanto a que mais se destacou foi aquela de caráter rápido, como a de jornais e revistas.

Neves e Francanela (2006.2) desenvolveram sua atividade na Floricultura Primavera, localizada na Rodovia SC, bairro Cacupé. Nesse ambiente, as alunas encontraram, além de mudas de folhagens, flores e plantas das mais variadas espécies, um espaço para a leitura. Os proprietários organizaram um canto de leitura com diversos materiais (jornais, revistas, livros) relativos e especializados em jardinagem, propiciando aos clientes o contato com uma leitura específica.

Vieira (2006.2) investigou a leitura na pintura impressionista, estudando 13 telas do século XIX que apresentavam indivíduos envolvidos com o ato de ler. Sua leitura constatou que as imagens analisadas apresentam uma leitura coletiva em detrimento de uma leitura individual. O espaço privado da casa, comum nas imagens do século XVIII, é substituído pelo espaço público da praça, dos bares, entre outros.

Mello, Flores e Souza apresentaram a leitura realizada por 21 internos da instituição Lar Recanto da Esperança, localizada no bairro Rio Vermelho. A casa de recuperação atende dependentes químicos que ficam internos por, no mínimo, seis meses. Os acadêmicos observaram os ambientes de leitura e os tipos de textos lidos pelos internos.

Como já se destacou, optou-se por apresentar, neste texto, uma pequena mostra dos trabalhos, que, no entanto, já evidenciam a variedade das formas de leitura que nos circundam.

\section{CONCLUSÃO}

As políticas públicas de leitura no Brasil sempre foram incipientes e provisórias. O Brasil é um país de 170 milhões de habitantes, entre os quais 16 milhões, de 15 anos ou mais, são analfabetos absolutos, e o mais aterrador é que 35\% desses já frequentaram os bancos escolares ${ }^{2}$. É urgente, pois, pensar as possibilidades de acesso aos suportes de escrita e de leitura, bem como verificar quais os espaços que possibilitam o contato com esses suportes.

\footnotetext{
${ }^{2}$ Mapa do Analfabetismo no Brasil, estudo produzido pelo Instituto Nacional de Estudos e Pesquisas Educacionais (INEP) a partir de dados de 2000 do IBGE e Programa das Nações Unidas para o Desenvolvimento (PNUD).
} 
Esse levantamento possibilita verificar que o leitor comum dribla os protocolos oficializados de leitura ideal e se apropria de outros. Que as pessoas, diferentemente do que se pensa, lêem, lêem muito: panfletos, catálogos promocionais, placas, cartazes, revistas, jornais etc. Os locais de leitura são os mais variados como: praias, shoppings centers, igrejas, rodoviárias, aeroportos, bibliotecas, escolas etc. A imagem de leitura e leitor convencionalizada como representativa de ascensão social e de poder - econômico e intelectual - aparece pouco nas imagens pesquisadas: encontramos o despojamento daquele que lê à beira da praia, entre a areia e o mar; as páginas viradas rapidamente ao pé da figueira, a leitura apressada entre um cafezinho e um bate-papo na lanchonete do shopping, leituras públicas em espaços públicos, leituras que não se fecham entre quatro paredes, nem se restringem a um determinado tipo de texto.

Uma segunda contribuição do trabalho realizado, embora não fosse seu objetivo, foi a de introduzir os alunos e as alunas no universo da pesquisa, seja apropriando-se dos instrumentos para a coleta de dados, nas possibilidades de análise dos dados ou na redação do texto escrito, pois este exercício conflui, de forma significativa, para as suas formações.

Esse "fazer pesquisa” propiciou o levantamento exploratório de locais, projetos e representações de leitura que circulam na grande Florianópolis. Pretende-se, com o projeto consolidado, constituir um banco de dados com entrevistas e imagens sobre leitura em nossa cidade que possa servir de subsídio de pesquisa para as diversas áreas do conhecimento.

\section{REFERÊNCIAS}

Abreu, M. (2001). Diferentes formas de ler. www.unicamp.br/iel/memoria/ensaios.

Amorim, A.; Dias, G.; Pedro, M.; Carvalho, E. \& Bueno, T. (2006.1). A leitura realizada pelos idosos do Asilo Irmão Joaquim. Trabalho mimeografado, UNISUL.

Cunha, I. C. (2005.2). A leitura de pára-choques de caminhões. Trabalho mimeografado, UNISUL.

Ferraz, S. R. da S. (2006.2). A leitura na Igreja. Trabalho mimeografado, UNISUL. 
Freire, P. (1982). A importância do ato de ler: em três artigos que se completam. São Paulo: Cortez.

Mello, A. D.; Flores, J. \& Souza, M. R. (2006.2). A importância da leitura na recuperação da adicção, na casa de recuperação Lar Recanto da Esperança. Trabalho mimeografado, UNISUL.

Neves, C. B.; Francanella, R. M. (2006.2). O prazeroso ato de ler. Trabalho mimeografado, UNISUL.

Pessoa, K. A. (2004.2). A leitura na Praça XV de Novembro. Trabalho mimeografado, UNISUL.

Poulain, M. (1997). Cenas de leitura na pintura, na fotografia, no cartaz, de 1881 a 1989. In: Fraisse, E. et al. (Orgs.). Representações e imagens de leitura. Trad. Osvaldo Biato. São Paulo: Ática.

Ribas, D.; Ribas, W. (2004.2). Lendo na ponta dos dedos. Trabalho mimeografado, UNISUL.

Silva, C. O.; Conceição, K. S.; Teixeira, T. (2006.2). A leitura no shopping Center. Trabalho mimeografado, UNISUL.

Silva, A. J. R.; Hauptli, R. A. (2006.2). Entre sol e mar: as leituras realizadas na Praia de Canasvieiras. Trabalho mimeografado, UNISUL.

Silveira, A.; Pereira, M. (2006.2). O prazer de ler na biblioteca. Trabalho mimeografado, UNISUL.

Vieira, P. N. (2006.2). A leitura na pintura impressionista. Trabalho mimeografado, UNISUL.

\section{Documentos}

Diretrizes básicas para a política nacional do livro, leitura e biblioteca. Brasil, Governo Federal, 2004.

Mapa do Analfabetismo no Brasil, estudo produzido pelo Instituto Nacional de Estudos e Pesquisas Educacionais (INEP) a partir de dados de 2000 do IBGE e Programa das Nações Unidas para o Desenvolvimento (PNUD).

Retratos do Brasil, pesquisa realizada pela Câmara Brasileira do Livro, Sindicato Nacional de Editores de Livros, Bracelpa e Abrelivros, dezembro de 2000 a janeiro de 2001.

\section{Onde se lê mais sobre o assunto}

Debus, E. S. D. (2006). Leitor, livro e leitura de ficção: a representação da leitura na fotografia escolar. In: Lenzi, L. H. C. et al. (Orgs.). Imagem: intervenção e pesquisa. Florianópolis: Ed. da UFSC. 
Kleiman, Â. B. (2001). Oficina de Leitura: Teoria \& Prática. 8.ed. Campinas, SP: Ed. Pontes.

Paulino, G. et al. (2001). Tipos de textos, modos de leitura. Belo Horizonte: Formato.

Presença Pedagógica (2001). Entrevista: Existe a leitura errada? Sírio Possenti. Ed. Dimensão. V.7.n.40. Jul/Ago.

\begin{abstract}
A AUTORA
Eliane Santana Dias Debus é doutora em Letras - Teoria Literária (PUCRS-2001). Professora no Pograma de Pós-Graduação em Ciências da linguagem na Universidade do Sul de Santa Catarina (UNISUL) atuando no curso de Letras e Pedagogia. Membro do projeto de investigação "Literatura Infantil e Educação para a Literacia”, em curso no LIBEC - Centro de Investigação em Literacia e Bem-Estar da Criança, da Universidade do Minho (Portugal). Autora dos livros: Monteiro Lobato e o leitor, esse conhecido (UFSC/UNIVALI, 2004) e Festaria de brincança: a leitura literária na Educação Infantil (Paulus, 2006).

e-mail: eliane.debus@unisul.br.
\end{abstract}

